\title{
SISMOTECTÓNICA DE LA REGIÓN CENTRAL DE COSTA RICA
}

\author{
Mario Fernández A. ${ }^{1} \&$ Javier Pacheco A. ${ }^{2}$ \\ 1) Centro de Investigaciones Geofísicas (CIGEFI), Universidad de Costa Rica \\ y Red Sismológica Nacional (RSN:ICR-UCR) \\ 2) Instituto de Geofísica, Universidad Nacional Autónoma de México (UNAM)
}

(Recibido 26/6/1996; Aceptado 3/11/1997)

\begin{abstract}
The seismicity and the faulting in an area of $5000 \mathrm{~km} 2$ of the central part of Costa Rica between $9.5^{\circ}$ $10.3^{\circ}$ latitude north and $83.5^{\circ}-84.5^{\circ}$ longitude west were studied. The faults were taken from recient geological maps of the area, and from the Geologic Map of Costa Rica $(1: 200,000)$ specially in areas where detailed studies have not been done. Earthquakes that ocurred between 1990-1994 were relocated with a tridimentional crustal model in order to find the best correlation between the epicenters and the faults. Focal mechanisms were done to characterize the types of fault.

It was proved that there are two main faulting trends: northwest and northeast. The northwest one is considered the most important because of the extention of the faults and the associates seismicity. Three fault systems were found, one in the southern flank of the Cordillera Volcánica Central, another one in the nortwestern flank of the Cordillera de Talamanca and the last one in the high lands of the Cordillera de Talamanca. Focal mechanisms suggest that most of the faulting is normal.
\end{abstract}

RESUMEN: Se estudió la sismicidad y el fallamiento en los $5000 \mathrm{~km} 2$ de la parte central de Costa Rica, localizados entre las coordenadas $9,5^{\circ}-10,3^{\circ}$ latitud norte y $83,5^{\circ}-84,5^{\circ}$ longitud oeste. Las fallas se tomaron de varios mapas geológicos recientes de la zona, aunque también se incluyeron fallas del Mapa Geológico de Costa Rica escala 1:200.000, sobretodo en aquellas áreas donde los estudios de campo detallados no han sido realizados. Con el fin de buscar la mejor correlación entre los epicentros y las fallas se relocalizaron temblores que ocurrieron en el período 1990-1994, utilizando el modelo de corteza tridimensional obtenido en el sector central del país. Para caracterizar el tipo de fallamiento se hicieron mecanismos focales con el programa focmec del Seisan System.

Se comprobó que el fallamiento en la zona tiene dos orientaciones preferenciales: NO y NE, el primero es el más importante tanto por la extensión de las fallas como por la sismicidad asociada. Se distingue muy bien un sistema de fallas en el flanco sur de la Cordillera Volcánica Central, otro en el borde noroeste de la Cordillera de Talamanca y un intenso fracturamiento en la estribaciones de esta última cordillera. Los mecanismos focales sugieren que este fallamiento es básicamente de tipo normal.

\section{INTRODUCCIÓN}

Desde tiempos históricos existe evidencia de actividad sísmica en la parte central de Costa Rica (Víquez, 1910; Tristán, 1912); los terremotos de Cartago (1841 y 1910), el de Fraijanes
(1888) y los de Toro Amarillo (1910, 1911 y 1912) así lo confirman. Esta actividad es pobremente conocida en lo que respecta a sus características físicas, porque no fue sino hasta 1888 que se instaló el primer sismoscopio en Costa Rica; pero no en cuanto a sus daños, ya que los 
terremotos de Cartago y Fraijanes fueron muy destructivos y causaron pérdidas de vidas humanas como en el caso de los de Cartago.

Con la instalación de las primeras redes de estaciones portátiles en el área estudiada en este trabajo (Montero \& Morales, 1984) y la red permanente a nivel nacional (RED SISMOLOGICA NACIONAL: ICE-UCR (RSN)) a partir de 1974, se empezaron a registrar importantes niveles de microsismicidad en los alrededores de San José, Alajuela y al sur de Cartago. Esta actividad era de baja magnitud, superficial, moderada en cuanto al nivel de ocurrencia y permanente. Pese a la baja magnitud de los sismos se consideraba muy importante para la zona, porque en ella están los principales centros económico-sociales del país.

La causa de esta sismicidad no se conoce con certeza, pero últimamente se le ha vinculado con un sistema de falla transcurrente que atravesaría la parte central del territorio nacional desde el océano Pacífico hasta el mar Caribe (Jacob et al., 1991; Plafker \& Ward, 1992; Güiendel \& Pacheco, 1992; Fan et al., 1993; Goes et al., 1993; Fisher et al., 1994; Protti \& Schwartz, 1994). Los estudios hechos sobre esta sismicidad han contado con poca información y la calidad de los datos ha sido afectada por las limitaciones instrumentales (equipo analógico) y aquella derivada de la carencia de un adecuado modelo de velocidades sísmicas para el territorio de Costa Rica. Por lo antes expuesto, se considera que el problema de la sismicidad superficial en la región central de Costa Rica no ha sido debidamente evaluado y es por eso que se realiza este trabajo, el cual pretende analizar integralmente la sismicidad y el fallamiento en un área de aproximadamente $5.000 \mathrm{~km}^{2}$, que incluye el Valle Central de Costa Rica y parte de las estribaciones de la Cordillera de Talamanca. Se han utilizado mapas estructurales recientes y se han relocalizado temblores con nuevos programas, un mejor modelo de corteza y formas de onda digitales.

\section{MARCO TECTÓNICO}

Costa Rica se encuentra en la placa Caribe (Fig. 1) cerca de la fosa Mesoamericana que es el límite entre dicha placa y la de Cocos, y la zona a partir de la cual la segunda placa se subduce bajo la litosfera de la primera. La dirección de convergencia es $\mathrm{N} 25^{\circ}-30^{\circ} \mathrm{E}$ y su velocidad varía entre $72 \pm 3 \mathrm{~mm} /$ año frente a las costas de Guatemala y $102 \pm 5 \mathrm{~mm} /$ año frente a la costa del Pacífico sur de Costa Rica (De Mets et al., 1990; Protti et al., 1994). En el norte de Costa Rica, la placa subducida tiene un ángulo de inclinación de $80^{\circ}$, en la parte central $60^{\circ}$, y en el sur no hay evidencia de la zona Wadatti-Benioff más allá de los $50 \mathrm{~km}$ de profundidad, considerándose que estas variaciones geométricas son consecuencia de las diferentes edades de la litosfera oceánica de la placa Cocos (Protti et al., 1994). Por este proceso de subducción, se originaron las cordilleras volcánicas de

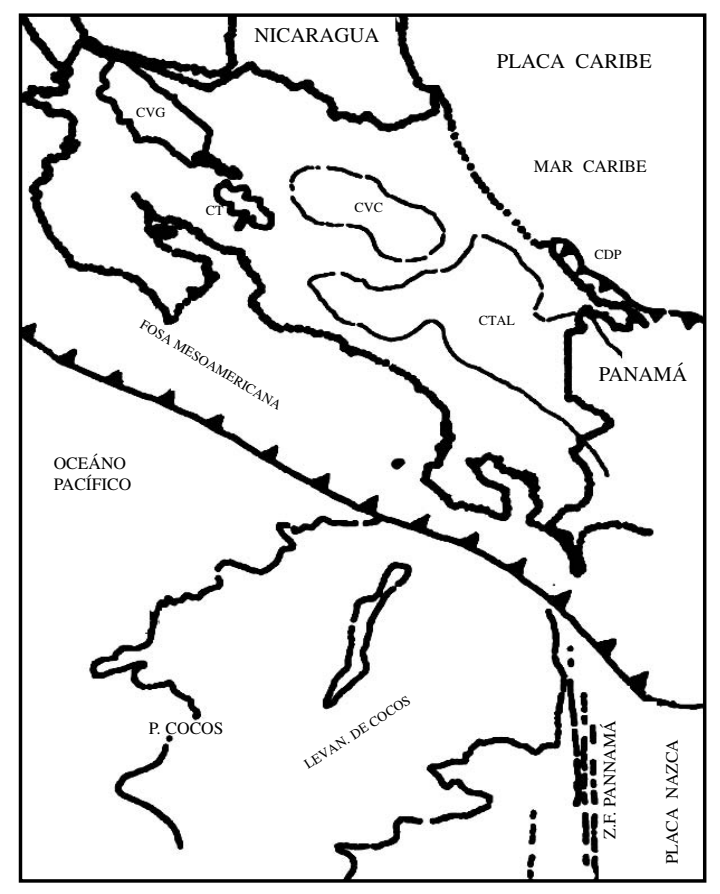

Fig. 1: Marco tectónico. El régimen tectónico de Costa Rica se debe a la interacción de las placas Caribe, Cocos y Nazca. Las dos primeras limitan a lo largo de la fosa Mesoamericana y las dos últimas a lo largo de la Fractura de Panamá. En el Caribe se encuentra el Cinturón Deformado de Panamá (CDP) que ha sido propuesto como un margen convergente dentro de la placa Caribe. P: placa; ZF: zona de fractura; CVG: Cordillera Volcáncia de Guanacaste; CT: Cordillera de Tilarán; CVC: Cordillera Volcánica Central; CTAL: Cordillera de Talamanca y LEVAN: levantamiento. 
Costa Rica (Central y de Guanacaste, Fig. 1) que forman parte de la cadena volcánica centroamericana.

En la costa pacífica, al sur de la frontera entre Costa Rica y Panamá, se encuentra el punto triple entre las placas Cocos, Caribe y Nazca (Fig. 1). El límite entre Cocos y Nazca es una falla transformante dextral mientras que el tipo de límite entre Nazca y Caribe no se ha definido aún (Adamek \& Tajima, 1987; Montero, 1994). Cerca de este punto se localiza el Levantamiento de Cocos que colisiona con la placa Caribe (Suárez et al., 1995) y se subduce superficialmente bajo ella (Montero, 1994; Protti et al., 1994); este Levantamiento arribó a la fosa Mesoamericana hace un millón de años (Londsdale \& Klitgord, 1978) y por la colisión que produce, la compresión y el efecto buoyante, ha contribuido al levantamiento de la Cordillera de Talamanca (Montero et al., 1992), que es la más alta de Centroamérica.

En el Caribe, frente a las costas de Costa Rica y Panamá está el Cinturón Deformado de Panamá (Bowin, 1976), que es un margen convergente localizado dentro de la placa Caribe. Según Mister \& Jordan (1978), el piso de la cuenca de Colombia se mueve hacia las costas arriba mencionadas. Evidencias de actividad en este margen son el fallamiento inverso y el plegamiento en la cuenca Limón sur (Astorga et al., 1991). El terremoto de Limón en abril de 1991 es atribuido por algunos autores a empuje relacionado con este cinturón (Fan et al., 1991; Plafker \& Ward, 1991; Protti \& Schwartz, 1994) aunque otros lo vinculan con empuje en el área trasarco relacionado al indentor constituido por el Levantamiento de Cocos (Montero, 1994; Suárez et al., 1995).

\section{DATOS}

Para el análisis sismotectónico se usaron fallas de las siguientes fuentes: Montero et al. (1991a), Arias \& Denyer (1990a,b; 1991), Denyer \& Arias (1990a,B), Montero et al. (1991d), Alvarado et al. (1988), Montero (1993), Denyer et al. (1994) y Mapa Geológico De Costa Rica
(1982). Los mapas de los trabajos referidos se elaboraron utilizando fotografías aéreas y trabajo de campo. Alineamientos de ríos se tomaron de las hojas topográficos escala 1:50 000 del Instituto Geográfico Nacional de Costa Rica; se añadieron en aquellas áreas con pocos lugares de referencia y/o fallas reconocidas.

Los datos sismológicos son de la RED SISMOLOGICA NACIONAL (RSN), administrada por la Escuela Centroamericana de Geología de la Universidad de Costa Rica (UCR) y el departamento de Geología del Instituto Costarricense de Electricidad (ICE). Esta red opera desde 1974, es de cobertura nacional y cuenta con 17 estaciones sismológicas de grabación digital, período corto y componente vertical, distribuidas en todo el país. Del total de estaciones, ocho están dentro de la zona estudiada y seis más en los alrededores de la misma con lo que se proporciona buena cobertura sísmica en la parte central de Costa Rica.

La RSN localiza sismos con una estructura de velocidades para onda $\mathrm{P}$ unidimensional determinada (con refracción sísmica) por Matumoto et al. (1977), quienes reportaron tres capas corticales con velocidades de 5,$1 ; 6,2$ y $6,6 \mathrm{~km} / \mathrm{s}$, con espesores de 8,$2 ; 12,9$ y $22,4 \mathrm{~km}$, sobreyaciendo al manto superior de $7,9 \mathrm{~km} / \mathrm{s}$. Este modelo es inadecuado porque se obtuvo para la zona norte del país y luego se generalizó a todo Costa Rica, uniformando así un complejo arreglo tectónico que sugiere una estructura heterogénea a través del territorio costarricense; además, la profundidad del Moho $(43,4 \mathrm{~km})$ no ajusta muy bien con los 20-30 km de espesor de la corteza asociados con márgenes de placa activos (Protti, 1994).

El procesamiento de las señales sísmicas (lecturas, localizaciones, mecanismos focales, etc) se realiza con el sistema SEISAN para análisis de temblores (Havskov \& Lindholm, 1992), que incluye una versión modificada para SUN del programa Hypocenter. Este sistema permite recolectar, manejar y almacenar muy fácil y rápidamente formas de onda, lecturas y los resultados de la localización. El sistema de registro de las formas de onda es digital lo cual garantiza precisiones en la lectura del orden de los milisegundos y por tanto, lecturas muy confiables. 


\section{MÉTODO}

Para alcanzar los objetivos propuestos se digitalizaron fallas, relocalizaron temblores y se hicieron inversiones de mecanismos focales.

Las relocalizaciones se hicieron con el programa SIMULTPS que fue escrito originalmente por Thurber (1983) y modificado por Eberhart-Phillips $(1986,1990)$. Es un programa diseñado para hacer inversión por tomografía, relocalizando previamente los temblores. Se recurrió a él porque a partir de un gran conjunto de soluciones previas, realiza rápidamente la relocalización de todos los sismos y porque ya tiene el modelo tridimensional de velocidades de Protti (1994), que difiere del anterior en lo siguiente: 1- fue obtenido con inversión por tomografía utilizando señales sísmicas de todo el país, 2- incluye variaciones de velocidad tanto horizontal como verticalmente, 3- explica la configuración tectónica de Costa Rica y no solo parte de ella como lo hace el modelo de Matumoto et al. (1977), 4- contiene tres anomalías de velocidad (superficial $=0-10 \mathrm{~km}$ ) en la parte central de Costa Rica, una baja $(4,2 \mathrm{~km} / \mathrm{s})$ y dos de alta $(5,6$ $\mathrm{km} / \mathrm{s}$ ) velocidad. La de baja se asocia a elevadas temperaturas bajo la cadena volcánica y las de alta a rocas ultramáficas y batolitos.

El primer paso del proceso de relocalización fue seleccionar los sismos de acuerdo a su ubicación espacial, pues interesaban solamente los superficiales $(0-30 \mathrm{~km})$ de la parte central de Costa Rica. Para esto, se recurrió a las lecturas y a la localización de cada sismo para determinar si el mismo tenía al menos cuatro arribos de onda P y errores de localización inferiores a $4 \mathrm{~km}$; en caso negativo el evento era descartado. Después de escoger los sismos adecuados para el estudio se corrieron nuevamente y de ellos se tomó el tiempo de viaje de las ondas sísmicas entre cada estación y el hipocentro, con el cual se determinaron nuevos residuos de tiempo de viaje que son la diferencia entre el tiempo observado y el predicho, están relacionado con cambios en los parámetros hipocentrales $(\mathrm{t}, \mathrm{x}, \mathrm{y}, \mathrm{z}$,$) y de velocidad ( \mathrm{v}$ ) y se expresan de la siguiente manera: $r_{i j}=\Delta t_{i}+\frac{\partial t_{i j}}{\partial x_{i}} \Delta x_{i}+\frac{\partial t_{i j}}{\partial y_{i}} \Delta y_{i}+\frac{\partial t_{i j}}{\partial z_{i}} \Delta z_{i}+\sum_{n=1}^{N} \frac{\partial t_{i j}}{\partial v_{n}} \Delta v_{n}(1)$

donde:

$$
\Delta t_{i}, \Delta \mathrm{x}_{i}, \Delta \mathrm{y}_{i}, \Delta \mathrm{z}_{i}, \Delta \mathrm{v}_{n}
$$

son perturbaciones a los parámetros iniciales de hipocentro y velocidad, y

$$
\frac{\partial t_{i j}}{\partial x_{i}}, \frac{\partial t_{i j}}{\partial y_{i}}, \frac{\partial t_{i j}}{\partial z_{i}}, \frac{\partial t_{i j}}{\partial v_{n}}
$$

son las derivadas parciales de los tiempos de arribo con respecto a las coordenadas del temblor y parámetros de velocidad, respectivamente. $\mathrm{N}$ es el número de parámetros de velocidad.

Los mecanismos focales se hicieron con el programa focmec, del SEISAN SYSTEM el cual busca automáticamente soluciones según un intervalo de grado dado y el mínimo de errores de polaridad. Para este trabajo, se buscaron todas las soluciones existentes cada 5 grados. Cada mecanismo focal de este trabajo tiene las siguientes condiciones: 9 o más polaridades, gap $<180^{\circ}$, un error en la polaridad si el número de ellas es 9 y 2 o más si su número es mayor, errores de localización inferiores a $3 \mathrm{~km}$ y un máximo de 30 soluciones todas consistentes y con pequeño rango de variación.

\section{ANÁLISIS SISMOTECTÓNICO POR ÁREAS}

En esta sección se hace un análisis detallado de la sismicidad y el fallamiento de la zona, con los siguientes propósitos: 1- establecer tendencias locales en uno y otro proceso en favor o en contra de la existencia de un sistema de fractura mayor, 2- determinar (cuando sea posible) cuales fallas están generando sismicidad, 3confirmar o refutar a Fan et al. (1991) quienes afirman que en la parte central de Costa Rica hay una difusa zona de fallas transcurrentes subparalelas que constituiría el límite tectónico entre la placa Caribe y el bloque de Panamá. Se correlacionan ambos procesos graficando las fallas y 
los temblores y analizando visualmente su coincidencia. Para lograr estos objetivos se utilizaron 2641 sismos (1543 fueron relocalizados y 1098 no relocalizados) con profundidades que varían entre 0-30 $\mathrm{km}$ y magnitudes entre 1-6 grados, y fallas de mapas a escala 1:50 000. Muchos de los nombres de éstas fueron tomados de los mapas mencionados y unas pocas fueron nombradas en este trabajo por razones de conveniencia a la hora de referirse a ellas en el texto.

Pese a que los epicentros están en la zona del país mejor cubierta con estaciones sísmicas, se relocalizaron los temblores con un nuevo modelo de corteza (Protti, 1994) buscando con ello la mejor ubicación de los mismos. Con las relocalizaciones se determinó que la variación promedio del error cuadrático medio (rms) respecto a las localizaciones previas osciló entre 0 y 0,19 segundos, la del error en la componente horizontal entre 0,20 y 0,84 $\mathrm{km}$ y la vertical en el rango de $0-2,62 \mathrm{~km}$. El hipocentro y el epicentro de los temblores relocalizados varió entre 0 y $2 \mathrm{~km}$ con respecto a localización preliminar. Protti et al. (en prep.) encontraron resultados similares e indican que las pequeñas diferencias se deben a que la mayoría de la información contenida en los residuos del tiempo de viaje fue puesta en la estructura de velocidad y a la buena cobertura de estaciones y buen número de tiempos de arribo con lo cual una simple estructura unidimensional produce soluciones aceptables.

Se graficaron mecanismos focales, los cuales ayudarían a sugerir tipos y orientaciones de las fallas. El área de estudio se dividió en tres zonas: flanco sur de la CVC, área de relieve plano entre la CVC y la Cordillera de Talamanca (Valle Central) y las estribaciones de la Cordillera de Talamanca. Para hacer un análisis más detallado, cada una de las zonas anteriores se subdividió en áreas de menor tamaño (Fig. 2). A continuación se describe la sismicidad, el fallamiento y los tipos de ruptura (mecanismos focales) en cada zona.

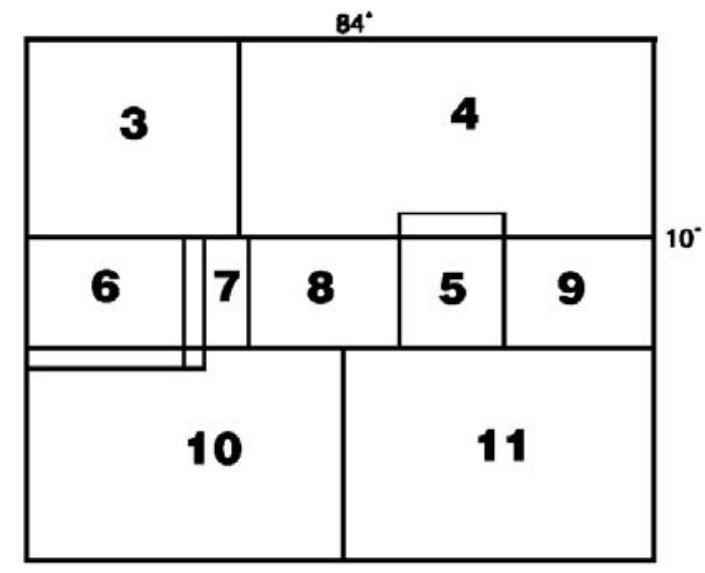

Fig. 2: Subdivisión del área de estudio. El número corresponde con las figuras que ilustran el texto. Las áreas 3, 4 y 5 pertenecen a la Cordillera Volcánica Central; 3: norte de Alajuela; 4: Bajo de la Hondura y 5: volcán Irazú. Las áreas 6, 7 y 8 son: 6: Puriscal; 7: oeste de San José; 8: San José. Las áreas 9, 10 y 11 son parte de las estribaciones de la cordillera de Talamanca; 9 abarca la hoja Tucurrique y las restantes comprenden las 4 hojas topográficas indicadas.

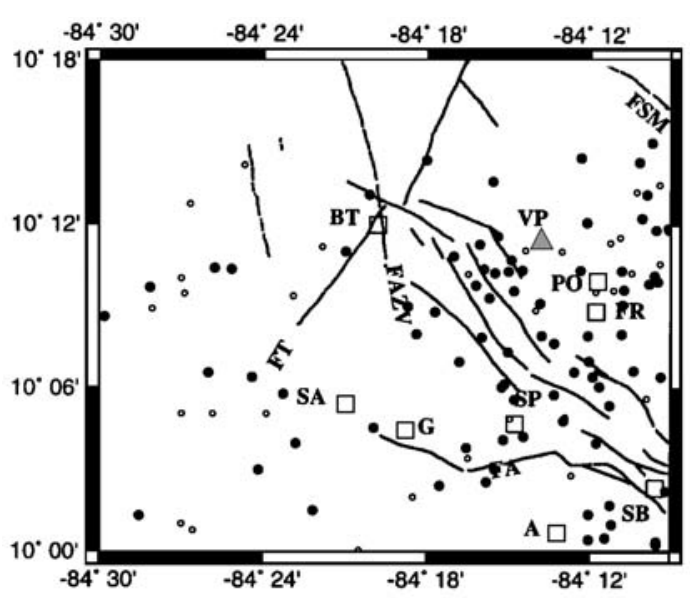

Fig. 3: Sismicidad y fallamiento en el sector norte de Alajuela. Las líneas continuas son las fallas, los círculos negros son temblores relocalizados y los círculos sin relleno son temblores no relocalizados. El triángulo indica volcán y los cuadrados representan localidades. Esta simbología se usará en las figuras siguientes. FA: falla Alajuela; FT: falla Toro; FAZV: falla Aguas Zarcas-Viejo FSM: falla San Miguel; VP: volcán Poás; A: Alajuela; SB; Santa Bárbara; SP: San Pedro de Poás; G: Grecia; SA: Sarchí: FR: Fraijanes; PO: Poasito y BT: Bajos del Toro. Un minuto $=1,85 \mathrm{~km}$. 


\section{CORDILLERA VOLCÁNICA CENTRAL (CVC)}

\section{Norte de Alajuela}

Incluye el tramo terminal del fallamiento del flanco sur de la CVC así como el flanco sur del volcán Poás (Fig. 3). A partir de Santa Bárbara de Heredia el sistema se ensancha, formando una amplia zona de lineamientos entre la mencionada localidad, Grecia y el volcán Poás. Justamente al sur de ese volcán los lineamentos se orientan un poco más hacia el norte con lo cual dejan de ser paralelos a la cordillera y más bien, tienden a atravesarla. Lo anterior no es el caso de la falla Alajuela, que se extiende desde el sureste de Santa Bárbara hasta el suroeste de Grecia. Esta falla tiene un visible escarpe en toda su extensión, es de rumbo aproximadamente E-O y ha sido considerada por Borgia et al. (1990) como una falla inversa de bajo ángulo.

Los rangos de profundidad y magnitud de los sismos son 1-28 km (promedio 11,32) y 1,0 4,6 grados, respectivamente. Algunos epicentros sugieren actividad en el sistema de fallas que se extiende desde Santa Bárbara hasta el flanco suroeste del volcán Poás (Fig. 3). Al noroeste del volcán Poás la sismicidad es baja e indica poca actividad en el fallamiento de ese sector; no obstante, allí han ocurrido sismos históricos que podrían estar relacionados con las fallas Aguas Zarcas-Viejo (FAZV) y Toro (FT). Hay sismicidad importante cerca de Poasito (PO) y Fraijanes (FR) donde deben hacerse estudios más detallados para determinar las pequeñas fallas que originan los temblores. La sismicidad entre Alajuela y Santa Bárbara fue generada por una falla de rumbo NE, ubicada al sureste de Alajuela; esta estructura se activó en 1990 y generó un sismo de magnitud 4,6 que produjo severos daños entre San Pedro de Santa Bárbara y Desamparados de Alajuela (Barquero \& Alvarado, en preparación).

\section{Bajo de la Hondura}

Esta zona incluye el volcán Turrialba, el volcán Barba, la depresión entre este volcán y el volcán Irazú (ligeramente al sur de esta zona) y las áreas al norte de estos rasgos geológicos que conforman el flanco norte de la CVC (Fig. 4).
Por aquí atraviesa (esquina suroeste del área) el gran sistema de lineamentos que se extiende desde el flanco suroeste del volcán Irazú (fuera de esta área) hasta el flanco suroeste del volcán Poás. En este trabajo tal sistema se denomina fallamiento del flanco sur de la CVC de Costa Rica. La componente de tal sistema en este sector son fallas de dirección noroeste entre San Isidro y Barba de Heredia (Fig. 4). Hacia el Bajo de la Hondura se ubican los lineamentos N$\mathrm{S}$ de los ríos Hondura y Patria, que han sido incorporadas como fallas en Denyer et al. (1994). Al noroeste del volcán Turrialba están las fallas Río Sucio, Alto Grande y Río Blanco (Montero \& Alvarado, 1995).

La sismicidad de la zona ha sido reconocida por Montero \& Dewey (1982) quienes hicieron un mecanismo focal compuesto con solución de falla inversa y Barquero et al. (1991) quienes reportan un temblor con intensidad IV en Cascajal de Coronado que se acompañó de fuerte ruido, según vecinos del lugar. Los temblores de esta zona se localizaron a profundidades variables entre 1 y $28 \mathrm{~km}$, siendo el promedio $11,78 \mathrm{~km}$; la magnitud varía entre 1,6 y 4,8 grados. En la figura 4 se muestra la distribución de sismos en la zona y, según se observa, hay un importante nivel de actividad en el área comprendida entre los volcanes Barba y Turrialba. Tanto los eventos no relocalizados (círculos son relleno) como los eventos relocalizados (círculos rellenos), confirman la continua ocurrencia de sismos en el área. La mayor concentración de ellos se localiza cerca de la intersección entre la falla Lara (FL) y la falla Hondura (FH). Se aprecia poca actividad sísmica en las fallas Alto Grande (FAG), Río Sucio (FRSU), Río Blanco y Blanquito (FB); sin embargo, las fallas Hondura $(\mathrm{FH})$, Lara y aquellas ubicadas en la esquina inferior izquierda del área parecen tener mayor actividad. También parecen tener actividad sísmica las fallas localizadas cerca del extremo norte de la falla Alto Grande y la pequeña falla localizada al noreste del volcán Barba.

Las zonas denominadas con las letras A, B y $\mathrm{C}$ tienen concentraciones importantes de sismos pero en ellas no se han encontrado expresiones superficiales de fallas. Algunos eventos relocalizados 


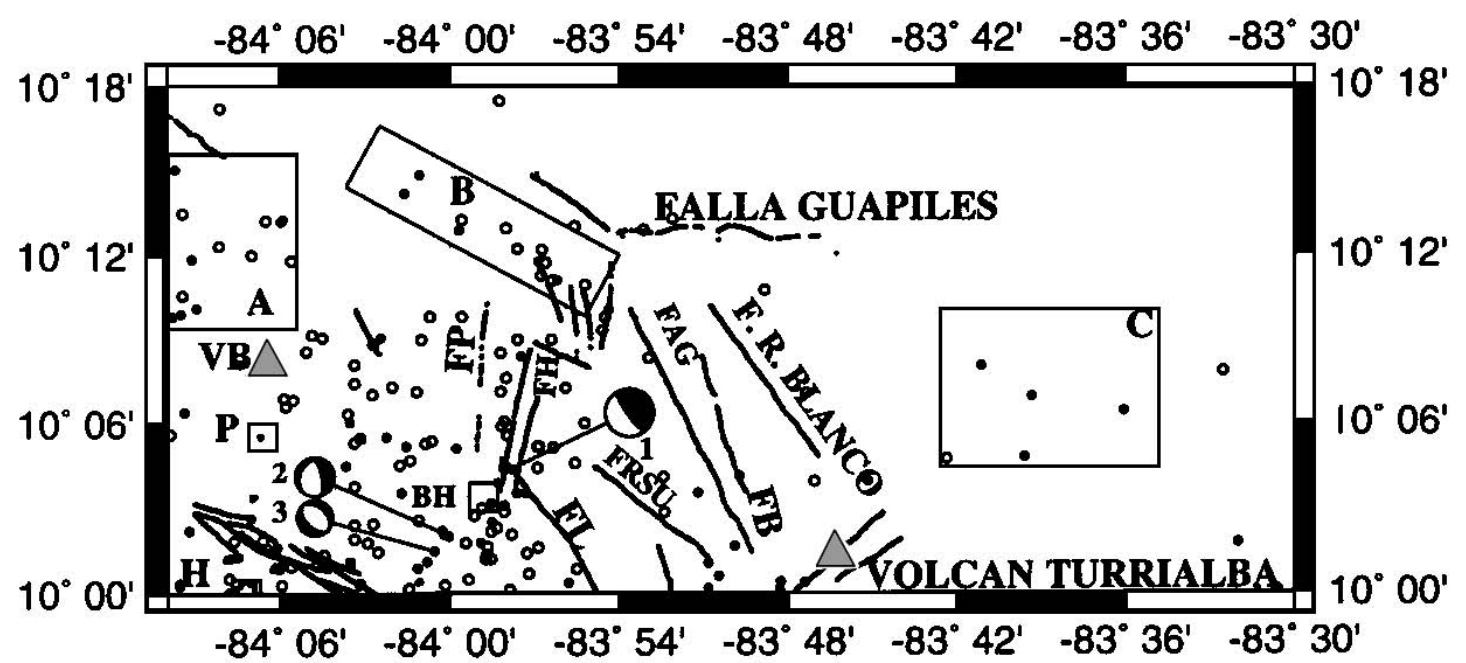

Fig. 4: Sismicidad y fallamiento en el Bajo de la Hondura. FH: falla Hondura; FP: falla Patria; FL: falla Lara; FRSU: falla Río Sucio; FAG: falla Alto Grande; FB: falla Blanquito; VB: volcán Barva; BH: Bajo de la Hondura; H: Heredia; P: Porrosatí. A, B, C: denominación de las áreas rectangulares.

y que se ubican en B podrían definir una falla de orientación noroeste, la cual se ha indicado en un rectángulo. En A y $\mathrm{C}$ la sismicidad está más dispersa y no da evidencia de fallamiento. Estas zonas deben ser analizadas con imágenes de satélite, fotografías aéreas e inspecciones de campo con el fin de conocer sus fallas.

El rumbo de los planos nodales del mecanismo $\mathrm{N}^{\circ} 1$ coincide muy bien con el rumbo de la falla Lara y el mecanismo $\mathrm{N}^{\circ} 2$ sugiere actividad tectónica en la falla Hondura. Se espera recopilar más mecanismos focales de esta zona en el futuro, para confirmar el tipo de movimiento en las fallas mencionadas, sugerido por las soluciones focales de este trabajo.

\section{Volcán Irazú}

El fallamiento de la zona se distribuye radialmente con respecto al cráter del volcán (Fig. 5); por el noroeste están los dos brazos de la falla Río Sucio (FRSU), por el noreste las fallas Felia (FE) y Ariete (FA) y por el sur la falla Irazú (FI). Otras fallas importantes son Lara (FL) y Nubes (FN), ambas localizadas al este-sureste del cráter. También se ha incluido un conjunto de lineamentos al sur de Pacayas y Capellades, de orientación este-oeste aproximadamente. Paniagua et al. (1993) ubican pequeñas fallas de rumbo NE entre el volcán Irazú y el volcán Turrialba y otra de orientación casi este-oeste que atraviesa el cráter principal del Irazú.

Sísmicamente, la zona es de baja actividad pero de gran importancia por los enjambres que en ella ocurrieron en 1982 y 1991. Para el primero, Güendel (1985) propuso una solución de falla inversa; dicha actividad sísmica se ubicó entre las fallas Elia y Ariete. El último enjambre inició luego del evento del 22 de diciembre de 1990 en la zona de Puriscal y es el mejor documentado hasta la fecha; la actividad se concentró en los alrededores del cráter sin un alineamiento particular, aunque gran parte de los sismos se localizaron en el extremo norte de la falla Irazú razón por la que se considera que esta fue una de las fallas más activas durante ese enjambre. El movimiento de las fallas durante el enjambre de 1991 afectó el sistema hidrotermal (Barquero et al., 1992), provocando emisiones fumarólicas en el cráter activo. La magnitud de los eventos generados durante los enjambres varía desde 1 a 4,2 grados y su profundidad entre 0 y $15 \mathrm{~km}$. Según la figura 5, también las fallas Lara y Nubes tienen importantes niveles de actividad sísmica. 


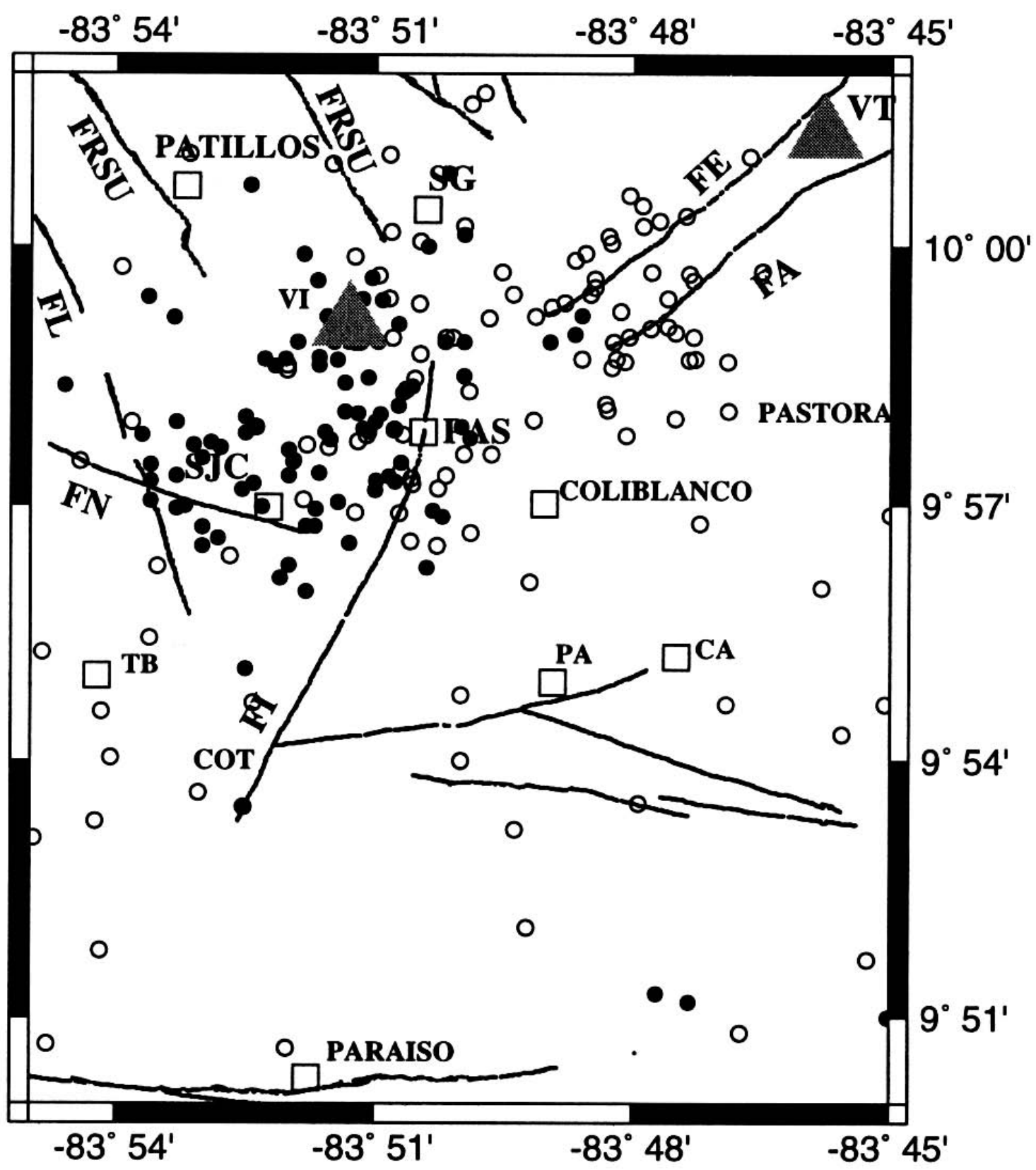

Fig. 5: Sismicidad y fallamiento en el volcán Irazú. FI: falla Irazú, FN: falla Nubes; FL: falla Lara; FRSU: falla Río Sucio (se ramifica); FE: falla Elia; FA: falla Ariete; VI: volcán Irazú; VT: volcán Turrialba; CA: Capellades; PA: Pacayas; TB: Tierra Blanca; SJC: San Juán de Chicuá; PAS: Pastora; SG: San Gerardo. 


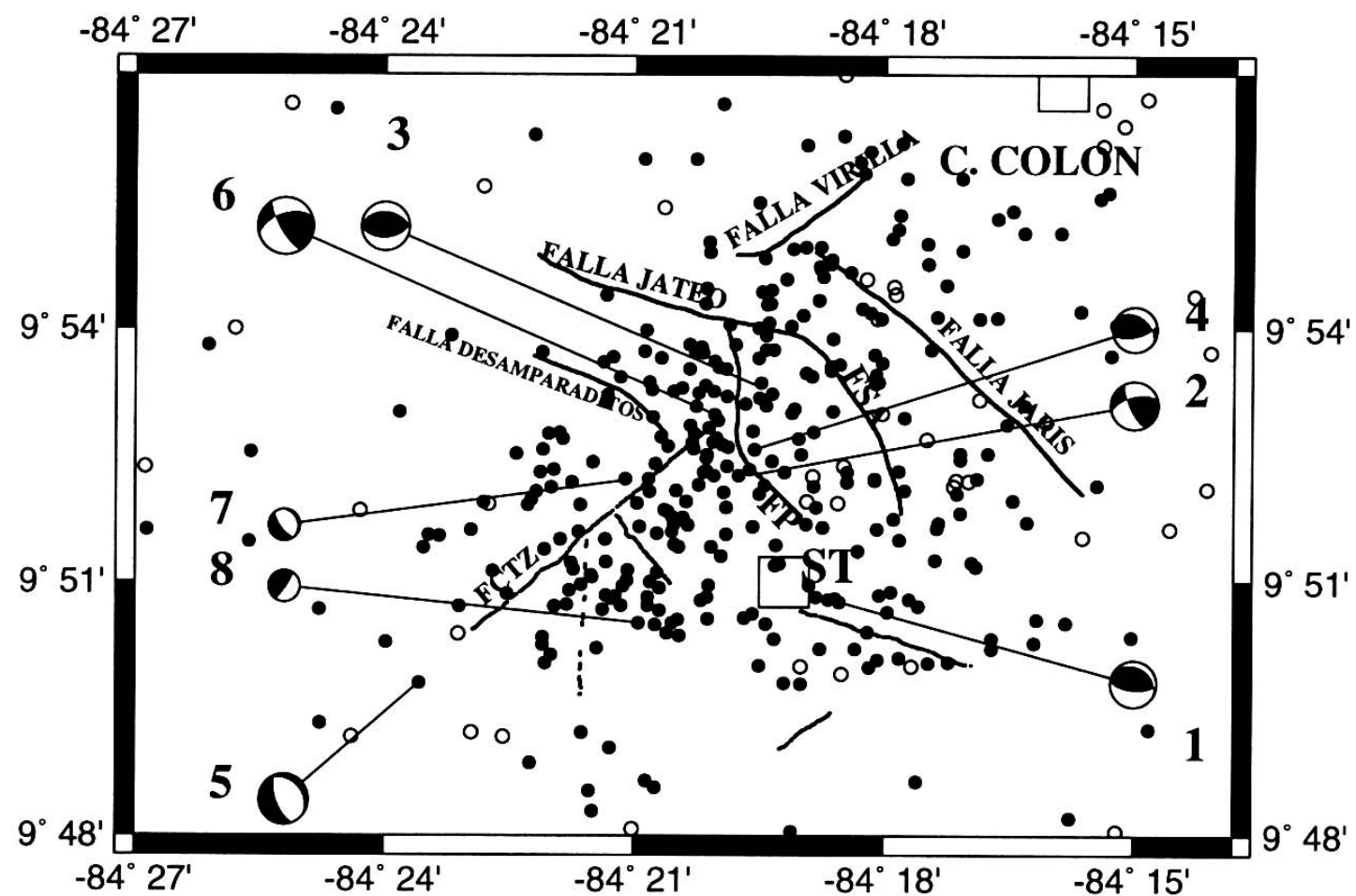

Fig. 6: Sismicidad y fallamiento de Puriscal. FCTZ: falla Cortezal; FP: falla Picagres; FSA: falla San Antonio; ST: Santiago de Puriscal.

VALLE CENTRAL

\section{Puriscal}

Montero et al. (1991) identificaron y describieron los lineamentos Jateo, Desamparaditos, San Antonio, Picagres, Virilla y Jaris (Fig. 6) los cuales hoy día se consideran fallas. Otras fallas fueron determinadas por Arias \& Denyer (1991).

En esta zona se había detectado poca actividad sísmica en el pasado, pero después del sismo de Cóbano (costa pacífica) en marzo de 1990 (Ms $7,1)$, se desató una intensa actividad sísmica en ella, que provocó incluso el desalojo parcial de la localidad de Santiago. El número de sismos ascendió aproximadamente a 30.000 , la mayoría de los cuales fueron tan pequeños que no se localizaron. De esa cifra, solamente 22 eventos alcanzaron magnitud mayor o igual a 4,0. Los tres eventos más fuertes fueron de magnitud 4,75 (30 de mayo), 5,0 (30 de junio) y 5,7 (22 de diciembre).
La relocalización de los sismos $[1 \mathrm{~km}<$ profundidad $(\mathrm{p})>30 \mathrm{~km}$; profundidad promedio $(\mathrm{pp})=9,25 \mathrm{~km} ; 1,5<$ magnitud (mag.) > 5,7] más importantes, confirma que ellos ocurrieron en un sector con más de 10 fallas pequeñas $(5-10 \mathrm{~km})$ que se habrían movido durante el enjambre de 1990. Es probable que por la fragilidad de los materiales no solo se indujo movimiento en otras fallas sino que generó nuevo fracturamiento (Arias \& Denyer, 1991). Aparentemente se inició el enjambre en las fallas localizadas al este de Santiago (el número de los mecanismos responde al orden cronológico en que ocurrieron los eventos) y luego migró la actividad hacia el noroeste-oeste. El último episodio del enjambre pudo haber estado relacionado con la actividad de la falla Cortezal, pues la orientación de esta coincide con la tendencia noreste de los sismos de la figura 6.

Los mecanismos focales son de los tres tipos: transcurrente, inversos y normales. De ellos 


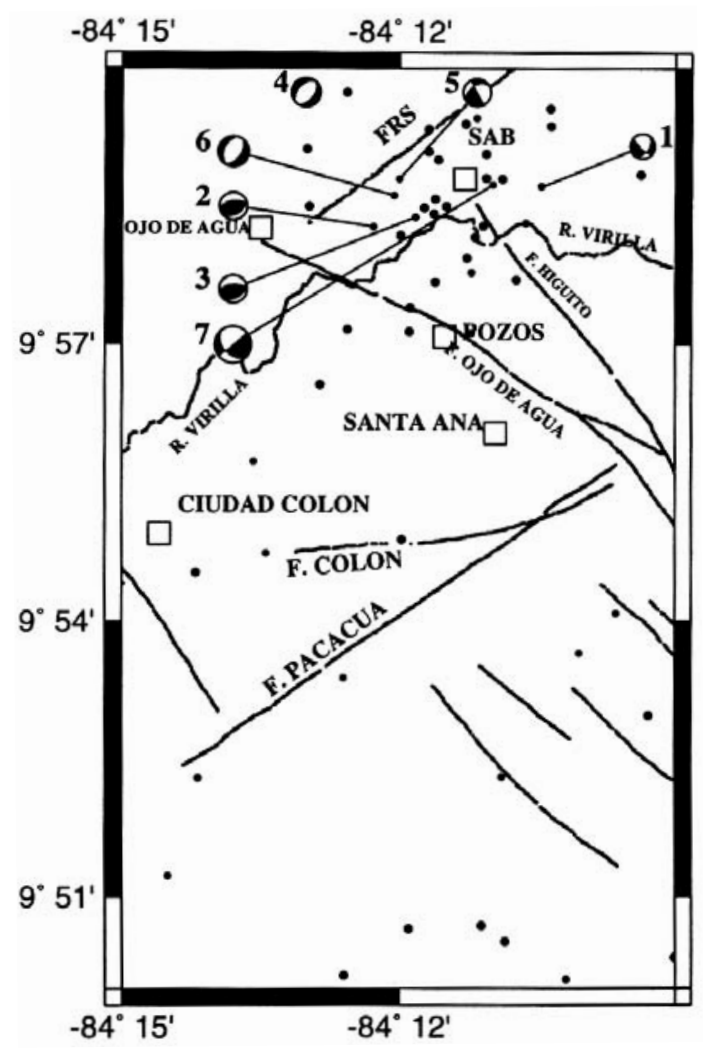

Fig. 7: Sismicidad y fallamiento al oeste de San José. FRS: falla Río Segundo; SAB: San Antonio de Belén.

se deduce que hubo importante movimiento de tipo inverso durante el enjambre. El mecanismo $\mathrm{N}^{\circ} 6$ corresponde con el evento de Piedras Negras del 22 de diciembre de 1990 ( $M d=5,7)$, fue elaborado con 21 polaridades, es transcurrente con alta componente inversa. La solución obtenida es consistente con la de la Universidad de Harvard, excepto el plano NE que tiene diferente buzamiento. Ambos planos de esta solución focal coinciden con fallas, uno con la falla Picagres y el otro con la falla Cortezal.

\section{Oeste de San José}

$\mathrm{Al}$ igual que en todas las zonas anteriores la tendencia de las fallas es noroeste, excepto aquellas ubicadas al sur de Santa Ana y Ciudad Colón cuya orientación es este-oeste y noreste (Fig. 7). El sistema más importante es aquel localizado al norte de Santa Ana. Fallas más pequeñas se localizan al sureste de Santa Ana. Estructuralmente la zona es muy compleja, específicamente en el sector San Antonio de Belén - Ojo de Agua donde convergen el sistema de fallas proveniente del sureste, el lineamiento Río Segundo y los lineamentos Virilla NE y SEE. Es oportuno recalcar que aquí termina el sistema de lineamentos del flanco NO de la Cordillera de Talamanca.

Los sismos de esta zona tienen magnitudes variables entre 2 y 4,4 grados, su profundidad promedio es $12 \mathrm{~km}$. La mayoría de los temblores se localizan cerca de San Antonio de Belén, entre las fallas Higuito, Ojo de Agua y Río Segundo y son del período 1992-1993.

El mecanismo 7 (Fig, 7) sugiere actividad en la falla Higuito. La diversidad de mecanismos focales es consistente con la complejidad estructural pero aún así se indica que la litología del lugar favorece el fracturamiento multidireccional tal como propusieron Montero et al. (1991), quienes arguyen que el terremoto de Piedras Negras del 22 de diciembre de 1990 $(\mathrm{MD}=5,7)$ no produjo fracturamiento lineal sino fracturamiento en diversas direcciones debido al diaclasamiento columnar del manto ignimbrítico donde ocurrió el evento. La litología es muy similar en ambos lugares.

\section{San José}

Esta zona incluye la mayor parte de lo que se ha denominado Valle Central. Se escogió para mostrar las principales fuentes sísmicas que amenazan a la ciudad de San José, donde se concentra la mayor parte de la población del país.

El sur del área es un sector intensamente fallado (Fig. 8) en el que se intersectan dos sistemas de fallas muy bien definidos: 1- el sistema de fallas noroeste que incluye las fallas Guarco (FG) - Coris (FC), Higuito (FH), Aserrí (FA), Granadilla (FG), Paracito-Rancho Redondo (FPA-RA) y Coronado (FCO); 2- el sistema de fallas noreste que se compone de las fallas Tablazo (FT), Salitral (FS) y San Rafael (FSR).

Los temblores se ubicaron entre 1 y 30 $\mathrm{km}$ de profundidad (promedio $=12,3 \mathrm{~km}$ ), su magnitud varió entre 2 y 4,8 grados. Al este de Escazú hay varios sismos que ilustran claramente la complejidad de ciertas áreas sísmicas 


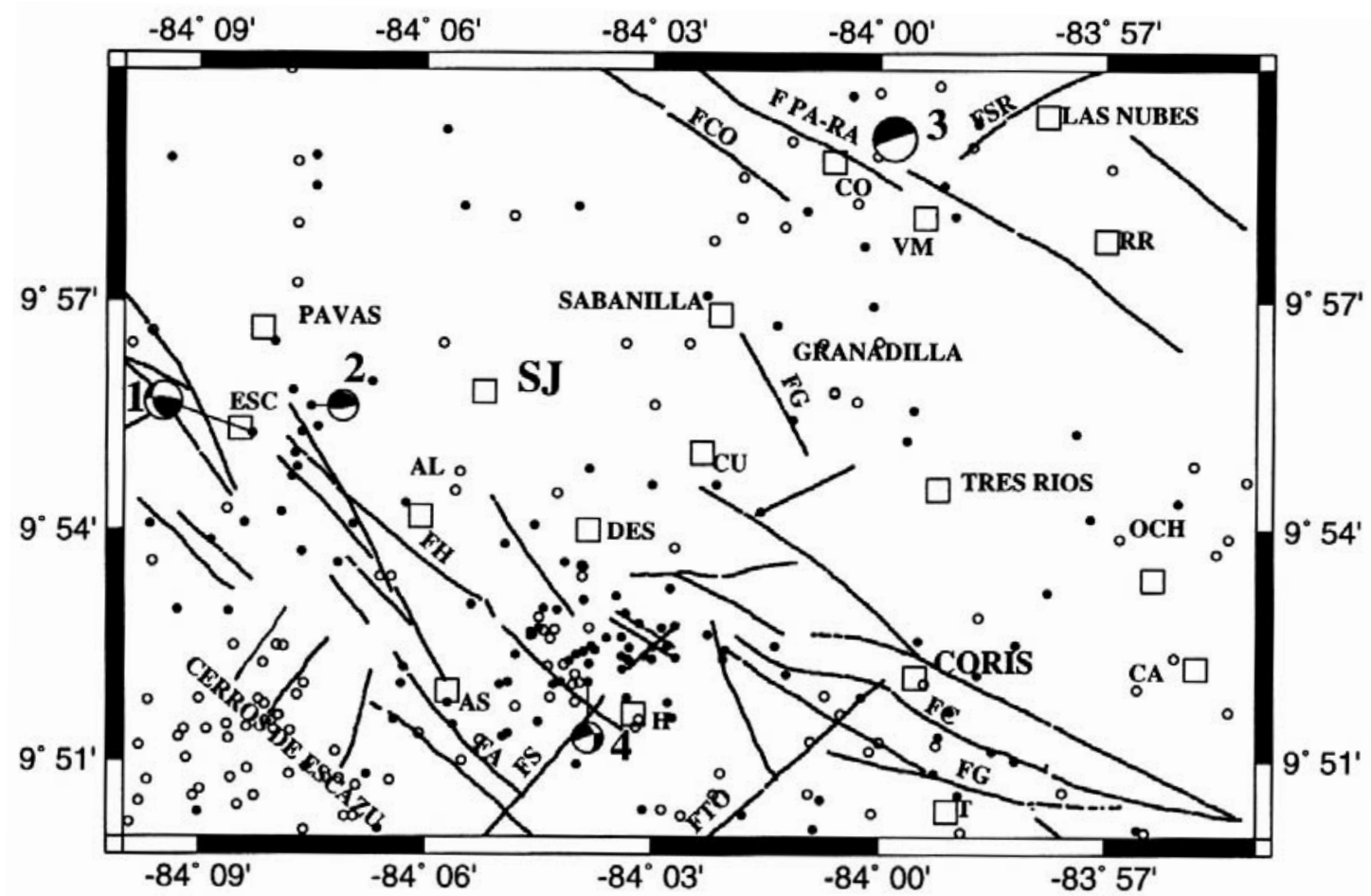

Fig. 8: Sismicidad y fallamiento alrededor de San José. FTO: falla Tablazo; FS: falla Salitral; FA: falla Aserrí; FG: falla Guarco; FC: falla Coris; FH: falla Higuito; FG: falla Granadilla; FCO: falla Coronado; FPA-RA: falla Paracito-Rancho Redondo; FSR: falla San Rafael; T: Tobosi; CA: Cartago; H: Higuito; AS: Aserrí; AL: Alajuelita; DES: Desamparados; OCH: Ochomogo; CU: Curridabat; ESC: Escazú; SJ: centro de la ciudad de San José; VM: Vista de Mar; RR: Rancho Redondo; CO: Coronado.

y lo difícil que puede resultar la interpretación de la fuente si no se cuenta con suficientes criterios. Se ven en la figura 8 siete epicentros muy cercanos unos de otros (los que se ubican en los extremos de los segmentos de las fallas Escazú, Higuito y San Antonio), tres de ellos se alinean con dirección N-S (los que están entre las fallas Higuito y San Antonio) y cuatro restantes hacia el NO. Justamente al oeste de ese grupo de epicentros y sobre la superficie de la ciudad de Escazú, hay un evento que no parece ser parte del grupo anterior y lo mismo se pensaría de otros eventos localizados más al sur del grupo analizado. Lo común de todos ellos es que se ubican en una zona de falla que termina al noreste de la ciudad antes mencionada. A primera vista, parece que no son las fallas del sistema las responsables de los eventos sino más bien otra de tendencia N-S, pero no se deduce lo mismo de los mecanismos focales pues éstos tienen diferentes soluciones en cuanto a la orientación de los planos, los que no concuerdan con la orientación de los alineamientos de los epicentros. De los mecanismos focales de Escazú se podría inferir movimiento transcurrente-inverso de dirección noroeste.

En julio y noviembre de 1994 se registró actividad sísmica entre Desamparados e Higuito de Desamparados. Algunos eventos de este enjambre se relocalizaron, concordando su ubicación con el alineamiento noroeste de los sismos localizados cerca de la traza de las fallas Coris y Guarco. Por lo anterior, es posible que las pequeñas fallas al sur de Desamparados sean una prolongación de las fallas Coris-Guarco y que fueran ellas las que se movieron durante dicho enjambre.

Las trazas de la falla Aserrí y aquellas perpendiculares al eje longitudinal de los Cerros de 


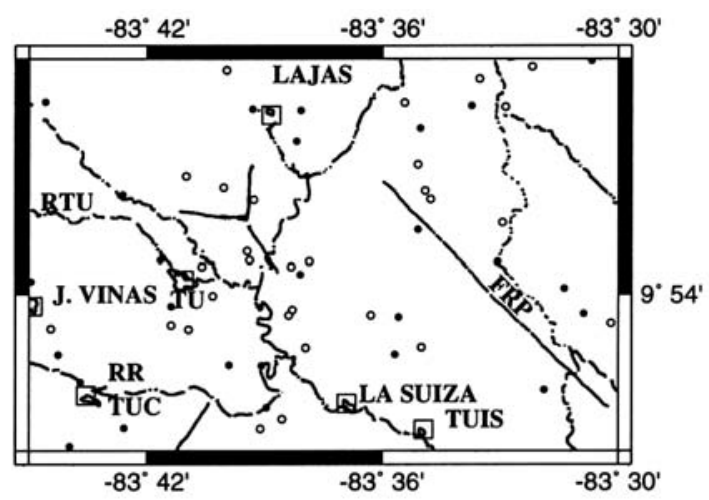

Fig. 9: Sismicidad y fallamiento en el área correspondiente a la hoja topográfica Tucurrique. FRP: falla Río Pacuare; TUC: Tucurrique; TU: Turrialba; RTU: río Turrialba; RR: río Reventazón.

Escazú, tienen alineamientos de epicentros asociados por lo que se consideran activas. También, se nota claramente el alineamiento de epicentros a lo largo de la falla Guarco-Coris. Si bien es cierto el número de sismos es bajo, la correlación entre epicentros y fallas es buena por lo que se deduce que tales fallas están activas. Hacia el norte, la falla Paracito-Rancho Redondo es la que presenta evidencia de actividad sísmica reciente por lo que se considera una falla activa; al norte de Pavas y San José hay varios sismos cuya fuente se desconoce. Será necesario hacer más estudios de campo para determinar posibles fallas en ese sector.

\section{ESTRIBACIONES DE LA CORDILLERA DE TALAMANCA}

\section{Area correspondiente a la hoja topográfica Tucurrique}

Desde el punto de vista sísmica la zona no es muy interesante y esto debido a que la sismicidad $(1 \mathrm{~km}<\mathrm{p}<30 \mathrm{~km} ; \mathrm{pp}=16,4 \mathrm{~km} ; 2<$ mag. $<4,7)$ no solo tiene un índice muy bajo sino que además está muy dispersa (Fig. 9), lo cual dificulta extraer conclusiones sobre lineamentos. Los sismos cerca de la falla Río Pacuare podrían indicar actividad tectónica en ella. El alineamiento de sismos entre Tucurrique y Juan
Viñas podría indicar la prolongación de la falla Tucurrique hacia Juan Viñas.

Esta zona es muy estable sísmicamente, ni siquiera los importantes temblores de Pejibaye de Turrialba (julio de 1993) han inducido sismicidad en ella.

\section{Area correspondiente a las hojas topográfi- cas Candelaria, Caraigres, Parrita y Dota}

Esta sección se acompaña de la figura 10 la cual comprende el área de las cuatro hojas topográficas. Para guía del lector, dicha área se dividiría simétricamente en cuatro partes: superior izquierda, superior derecha, inferior izquierda e inferior derecha. Las hojas topográficas correspondientes, en el mismo orden, son: Candelaria, Caraigres, Parrita y Dota.

El fallamiento de la zona está orientado tanto al noreste como al noroeste, se compone de fallas relativamente grandes. Las fallas Candelaria y Jaris (FC y FJ, Fig. 10), son las más grandes e importantes del área y su movimiento es transcurrente según Arias \& Denyer (1990a) y Denyer \& Arias (1990b).

La mayor parte de sismos graficados en la parte superior izquierda (hoja Candelaria) ocurrieron simultáneamente con la secuencia de temblores que en 1990-1992 afectó a la región de Puriscal; es probable que el campo de esfuerzos local que originó el enjambre referido haya activado fallas de esta zona las cuales, como se ve en la figura, no han sido mapeadas (no hay trazas de falla donde se ubican los sismos). En las inmediaciones de las fallas Venado (FV), Tigre (FT), Tulín y Zapatón y Candelaria se observa muy poca actividad. Más activos son los pequeños segmentos paralelos a la falla Candelaria (a la derecha de ella en la figura 10). La profundidad promedio de los sismos de Candelaria es de 11,21 km y la máxima magnitud allí registrada es 5,0.

Los rangos de magnitud y profundidad de los sismos de Caraigres (parte superior derecha) son 1,2 - 4,9 grados y 1 - $30 \mathrm{~km}$ respectivamente, el promedio de la profundidad de los temblores es $12,7 \mathrm{~km}$. Casi todas las fallas de esta sub-área tienen sismicidad en su cercanía, pero sobresalen las fallas Resbalón (FR), Salitral (FS), Tablazo (FTO), Patio de Agua (FPA) y Falla Corralillo 


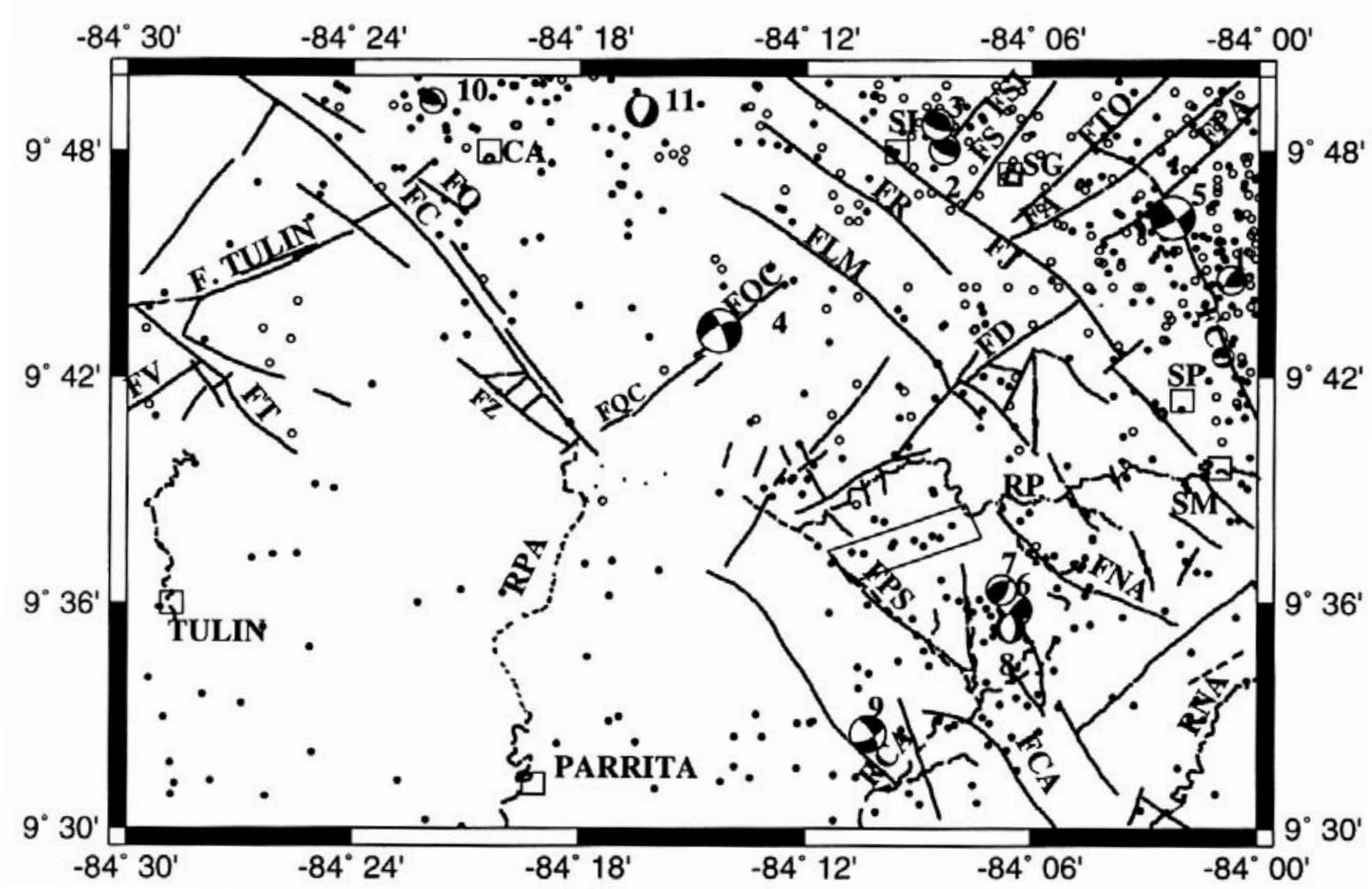

Fig. 10: Sismicidad y fallamiento en el área correspondiente a las hojas topográficas Candelaria, Caraigres, Parrita y Dota. FCA: falla Cañas; FPS: falla Palo Seco; FNA: falla Nápoles; FD: falla Delicias; FCO: falla Corralillo; FQC: falla Quebrada Colorado; FZ: falla Zapatón; FV: falla Venado; FC: falla Candelaria; FQ: falla Queverí; FLM: falla La Mesa; FR: falla Resbalón; FJ: falla Jaris; FPA: falla Patio de Agua; FA: falla Alumbre; FTO: falla Tablazo; FS: falla Salitral; FSI: falla San Ignacio; RCA: río Cañas; RNA: río Naranjo; RP: río Pirrís; RPA: río Parrita; SM: San Marcos de León Cortés; SP: San Pablo de León Cortés; SI: San Ignacio de Acosta; CA: Candelaria.

(FCO). Muchos de los sismos asociados a estas fallas ocurrieron después del temblor de Corralillo (agosto 1991, Ml = 4,9); este evento fue atribuido a la falla Corralillo (Montero, 1993). En la figura 10 se aprecia claramente el agrupamiento de temblores a lo largo de dicha falla, lo cual confirma que es una de las más activas de Caraigres.

Parrita (parte inferior izquierda) es una zona de muy baja actividad sísmica superficial $(4 \mathrm{~km}$ $<\mathrm{p}<30 \mathrm{~km} ; \mathrm{pp}=20,75 \mathrm{~km} ; 1,6<$ mag. $<4,8)$, la cual además está muy dispersa (Fig. 10). Los rasgos topográficos no permiten identificar fuentes.

Los sismos $(1 \mathrm{~km}<\mathrm{p}<30 \mathrm{~km} ; \mathrm{pp}=19,6 \mathrm{~km}$; $1,7<$ mag. $<4,1)$ de Dota (parte inferior derecha) se concentran cerca de los alineamientos formados por los ríos, siendo los más importantes el Pirrís (RP), Cañas (RCA) y Naranjo (RNA). El Pirrís es desviado dos veces en forma muy brusca y en dirección noroeste-sureste en concordancia con la orientación de las fallas Palo Seco (FPS) y Nápoles (FNA). Las fallas que presentan mayor evidencia de actividad reciente son: Palo Seco, Cañas (FCA), y Nápoles. Se propone una falla en el área donde se han encerrado varios epicentros alineados en dirección noreste. Una característica de la sismicidad de la hoja Dota (y también Parrita) es su mayor profundidad respecto a otras zonas; aquí ocurren muchos sismos con profundidades que oscilan entre los 20 y $30 \mathrm{~km}$.

Los mecanismos inversos y transcurrentes dominan en la zona. Los mecanismos 4 y 5 fueron tomados de las bases de la RSN; ambos coinciden muy bien con fallas geológicas, el $\mathrm{N}^{\circ}$ 4 con la falla Quebrada Colorado (FQC) y el $\mathrm{N}^{\circ}$ 5 con la falla Corralillo. Este último es un mecanismo compuesto obtenido con la sismicidad asociada al sismo del 8 de agosto de 1991 y fue 


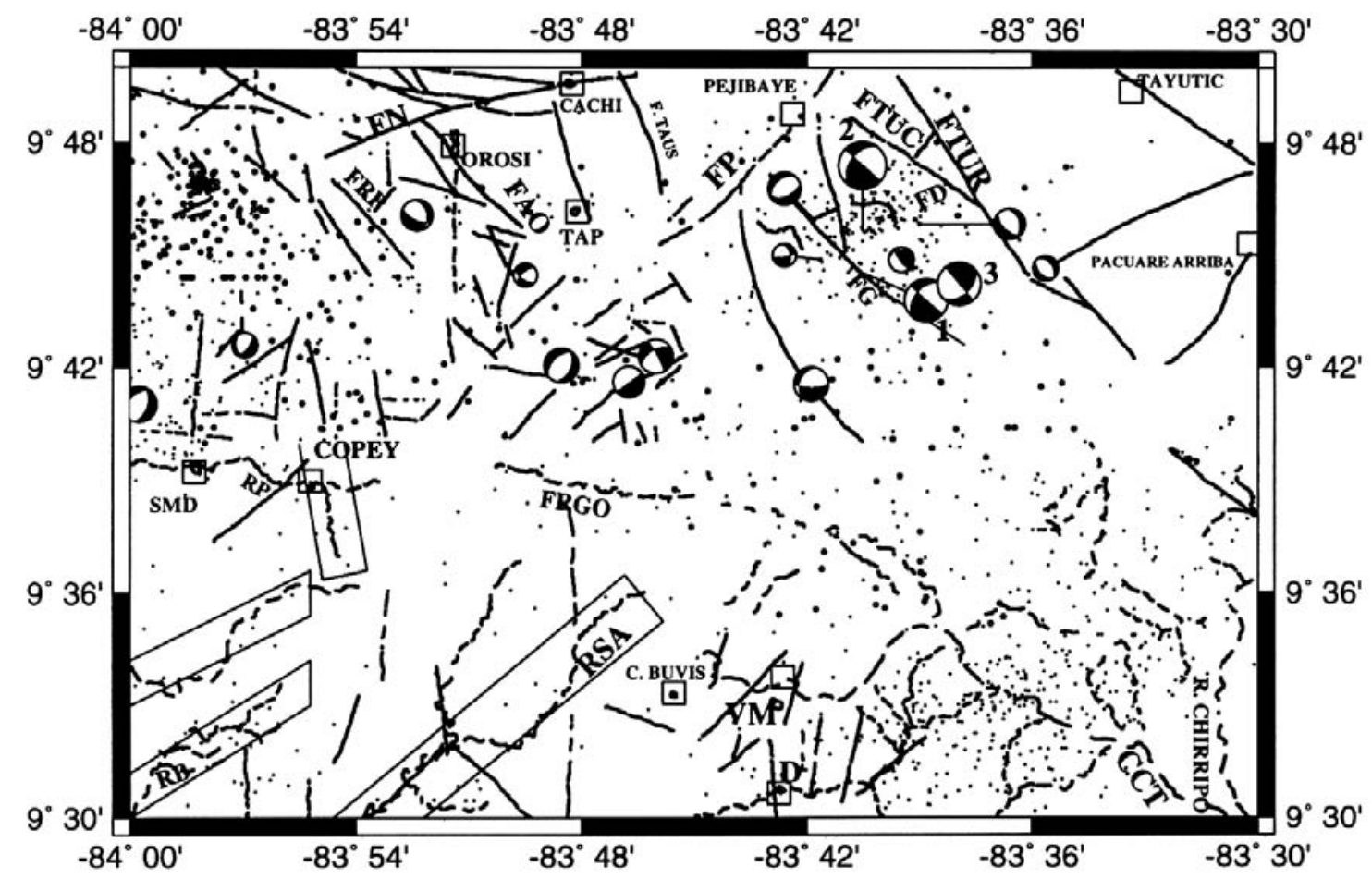

Fig. 11: Sismicidad y fallamiento en el área correspondiente a las hojas topográficas Tapantí, Pejibaye, Vueltas y Cuericí. FRGO: falla Río Grande de Orosi; FG: falla Gata; FD: falla Danta; FP: falla Pejibaye; FTUC: falla Tucurrique; FTUR: falla Turrialba; FAO: falla Aguacaliente-Orosi; FRP: falla Río Parrita; FN: falla Navarro; RB: río Brujo; RSA: río Savegre; RP: río Pirrís; CCT: cordillera de Talamanca; C: cerro; D: División; VM: Villa Mills; SMD: Santa María de Dota; TAP: Tapantí.

ubicado en el punto donde ocurrió el evento principal. Los mecanismos $\mathrm{N}^{\circ} 2$ y 3 son consistentes con el fallamiento inverso que Arias \& Denyer (1990a) cartografiaron cerca de San Ignacio de Acosta (SI).

Area correspondiente a las hojas topográficas Tapantí, Pejibaye, Vueltas y Cuericí

Esta sección se acompaña de la figura 11, donde la parte superior izquierda corresponde a la hoja Tapantí, la superior derecha a Pejibaye, la inferior izquierda a Vueltas y la inferior derecha a Cuericí. Esta figura es una continuación de la figura 10 por el sector este.

En la parte norte del área (Fig. 11) están trazadas las principales fallas del sureste de Cartago y la sección inicial del sistema de fallas Guarco-Coris, que se extienden desde el sureste de Cartago hasta el sureste de San José y constituyen la primera sección de un sistema mayor que corre por el flanco noroeste de la Cordillera de Talamanca, y en algunos tramos, al pie de ella. Son fallas de rumbo casi este-oeste excepto la falla Navarro (FN) que se orienta un poco más al suroeste; perpendicular a ésta hay otro sistema de orientación noroeste entre las que destacan Río Patarrá (FRP), Aguacaliente-Orosi (FAO) y Taus. En la zona de Pejibaye, fallas reconocidas (Barquero \& Peraldo, 1993) son: 1- falla Pejibaye (FP): se orienta al $\mathrm{N} 50^{\circ} \mathrm{E}$, buza $65^{\circ}$ hacia el sureste y es de tipo normal; 2- falla Atirro (falla Tucurrique FTUC + falla Turrialba FTU): es de rumbo $\mathrm{N} 40^{\circ} \mathrm{O}$, aparentemente es de tipo normal y se bifurca formando la falla Tucurrique y la falla Turrialba; 3- falla Danta (FD): la conforman los alineamientos de las quebradas Honda, Danta y Chanchera, es perpendicular a la falla Atirro y de tipo normal. El fallamiento de desplazamiento 
normal ha sido propuesto por Valdez \& Mora (1985; en Barquero \& Peraldo, 1993). En Vueltas y Cuericí hay pocas fallas cartografiadas, lo cual se debe en parte a que son áreas muy montañosas y de difícil acceso, sobretodo Cuericí que abarca parte de la cresta de la Cordillera de Talamanca (CCT).

En Tapantí ha habido y hay gran actividad sísmica $(1 \mathrm{~km}<\mathrm{p}<30 \mathrm{~km}$; pp = 12,53 km; 1,1 $<$ mag. $<4,6)$. Tal actividad se concentra principalmente en el extremo izquierdo del área (Fig. 11), concordantemente con pequeñas fallas de la zona. En el extremo suroeste de la falla Navarro hubo un enjambre sísmico en 1980 (Aguilar, 1984). Fallas conocidas como Aguacaliente-Orosi y el tramo inicial del sistema Guarco-Coris, no muestran gran actividad.

La sismicidad de Pejibaye $(1 \mathrm{~km}<\mathrm{p}<30$ $\mathrm{km} ; \mathrm{pp}=11,21 \mathrm{~km} ; 1,4<\operatorname{mag} .<5,6)$ está asociada al evento principal de la secuencia de julio de 1993, se localiza entre las fallas Tucurrique y Gata y se orienta preferencialmente en dirección suroeste-noreste, similar a la dirección de la falla Danta. Es posible que el evento principal haya inducido movimiento en la falla Danta y por eso se observa un alineamiento de epicentros en esa dirección. Se nota cierto nivel de actividad en las fallas Pejibaye y Tucurrique.

Al igual que en otras áreas, los temblores localizados en la hoja Vueltas ocurren en un rango de profundidades que oscila entre 1 y 30 $\mathrm{km}$, siendo su promedio $14 \mathrm{~km}$. En cuanto a su magnitud, las mismas varían entre 1,6 y 4,8, predominando aquellos sismos con magnitudes entre 2 y 3 . En toda la zona se observa concordancia entre alineamientos sísmicos y alineamientos de ríos, o sea, casi todos los epicentros se localizan cerca del cauce de los ríos principales de la zona. Tal es el caso de los ríos Pirris, Brujo, Savegre y Grande de Orosí. Este último, por el evidente alineamiento sísmico cerca de él, es propuesto como una falla activa (FRGO). Las áreas rectangulares, por los alineamientos epicentrales en ellas, sugieren fallas en sus respectivas direcciones. El río Brujo parece estar en un fracturamiento suroestenoreste con ramificaciones laterales. En el tramo inicial del área rectangular que incluye al río Savegre, hay una falla de orientación noreste que coincide con el rumbo del río en el extremo final de la misma y aparte de ello, se observan algunos epicentros en el principio, medio y final del área rectangular. Según lo anterior, el área estaría controlada por un fracturamiento principal de rumbo suroeste-noreste.

La sismicidad en la hoja Cuericí $(1 \mathrm{~km}<$ $\mathrm{p}<30 \mathrm{~km}$; pp = 9,52 km; 1,5< mag. $<4,7)$ ocurre en áreas cubiertas por lutitas, areniscas y calizas de las formaciones Uscari, Térraba y Brito entre otras. Mientras las rocas plutónicas se comportan competentemente, las sedimentarias resultan frágiles ante los esfuerzos aplicados y se fracturan intensamente. Esta zona se activó después del terremoto de Golfito en abril de 1983 y generó un sismo de magnitud Ms $=6,1$, cerca de esta zona (al sur) y gran cantidad de réplicas que se ubicaron entre División y el río Cuerici (Boschini et al., 1988). Lo mismo ocurrió después del terremoto de Limón $\left(\mathrm{M}_{\mathrm{W}}=7,6\right.$; Barquero \& Rojas, 1994), ocasión en la que se originó un sismo de magnitud 5,5 (al sur de la zona). También después del terremoto de Cóbano $(\mathrm{Ms}=7,1)$ hubo cierta actividad cerca del río Cuericí (Barquero et al., 1991). Desde el evento de Limón no ha cesado la ocurrencia de sismos en la zona, pero esto se considera normal después de un evento fuerte; probablemente la actividad disminuya paulatinamente hasta llegar a desaparecer por completo. Los sismos se concentran en una nube de orientación suroeste-noreste (Fig. 11), en fuentes sismogénicas localizadas casi en la cresta de la cordillera. La alta densidad de epicentros con orientación predominante sugiere un fracturamiento intenso pero de poca extensión, aunque también se debe considerar que la falta de estaciones en la zona podría ser la causa de la dispersión de los eventos (es la zona donde la magnitud del error horizontal es mayor). Casi todas las fallas ubicadas en la hoja Cuericí tienen actividad sísmica asociada.

Los mecanismos focales tipo normal son los que predominan en la zona. No obstante, los numerados que corresponden con los principales eventos de la secuencia de Pejibaye (1983), indican que el movimiento principal en las fallas que los originaron, fue de tipo transcurrente con 
componente inversa; esos mecanismos tienen en común un plano de rumbo noroeste, que coincide con el rumbo de las principales fallas de la zona de Pejibaye. Por esto y por la ubicación de estos sismos, se considera que fue la falla Gata la que originó tales temblores.

\section{CONCLUSIONES}

Se desprende del análisis de la sismicidad y el fallamiento de las anteriores zonas que en la parte central de Costa Rica hay un patrón conjugado de fallas con orientación noroeste-sureste y noreste-suroeste, respectivamente. El sistema de fallas de orientación noroeste es el mejor definido y el que posee las fallas más extensas; tiene su mejor expresión al suroeste de la zona estudiada, principalmente en las estribaciones de la Cordillera de Talamanca y corresponde con el área mejor cubierta de sismos dentro de la región total en estudio. Las fallas no muestran continuidad ni hacia el noreste ni hacia el noroeste, razón por la cual no definen (al menos superficialmente) una estructura tectónica mayor. Estos resultados no son consistentes con la propuesta de Fan et al. (1991), quienes indican que en la parte central de Costa Rica hay una zona difusa de fallas transcurrentes subparalelas.

De acuerdo a los mecanismos focales, en la parte central de Costa Rica el movimiento en las fallas es muy variado: hay desplazamientos normales, inversos y transcurrentes. Importantes eventos con mecanismo de tipo transcurrente como los mayores de la secuencia de Pejibaye y el de Corralillo sugieren activación de fallas con rumbo noroeste.

En la Cordillera de Talamanca y sus estribaciones se concentra la actividad sísmica. Probablemente, los procesos orogénicos que llevaron a la formación de la misma, contribuyó a la deformación cortical que hoy día se manifiesta mediante actividad sísmica superficial y que se activa con la ocurrencia de grandes temblores en otros sectores del país. En el flanco sur de la Cordillera Volcánica Central hay sismicidad con moderado nivel de ocurrencia.
Se observó alta correlación entre el fallamiento cartografiado y los alineamientos sísmicos en el Bajo de la Hondura, sureste del volcán Poás, Puriscal, sur de San José, Caraigres, Tapantí y Pejibaye. En las restantes áreas no es muy evidente la correlación, quizá porque no son muchos los sismos graficados. Los temblores ocurren en zonas de fallamiento preexistente, en algunos casos en áreas donde intersectúan varias fallas y cuando una se mueve, induce movimiento en las otras, como parece haber ocurrido en los alrededores de San Antonio de Belén, Escazú y al sur de San José. Las áreas de ruptura o zonas de activación son pequeñas, no se observó actividad continua a lo largo de las grandes fallas lo cual indica que son muy estables.

\section{AGRADECIMIENTO}

Se agradece profundamente al International Development Research Centre (IDRC) de Canadá por el soporte económico para realizar esta investigación. Asimismo, nuestro sincero agradecimiento al personal de la Oficina Regional del IDRC para América Latina y el Caribe (LACROP) y al del Instituto Panamericano de Historia y Geografía (IPGH) por su gran colaboración durante la investigación. También se agradece al Dr. Marino Protti por facilitar el programa para la relocalización de temblores y la instrucción al respecto.

\section{REFERENCIAS}

ALVARADO, G., MORALES, L. D., MONTERO, W., CLIMENT, A. \& ROJAS, W., 1988: Aspectos sismológicos y morfotectónicos en el extremo occidental de la Cordillera Volcánica Central de Costa Rica. - Rev. Geol. Amér. Central, 9: 75-98.

ARIAS, O. \& DENYER, P., 1990a: Geología de la hoja Caraigres (mapa 1:50.000) - Instituto Geográfico Nacional, San José, Costa Rica. 
ARIAS, O. \& DENYER, P., 1990b: Geología de la hoja Río Grande (mapa 1:50000) - Instituto Geográfico Nacional (IGN), San José, Costa Rica.

ARIAS, O. \& DENYER, P., 1991: Aspectos neotectónicos de Puriscal y alrededores, Costa Rica. - Rev. Geol. Amér. Central, 12: 83-95.

ARIAS, O. \& DENYER, P., 1991: Estructura geológica de la región comprendida en las hojas topográfica Abra, Caraigres, Candelaria y Río Grande, Costa Rica. - Rev. Geol. Amér. Central, 12: 61-74

ASTORGA, A., FERNANDEZ, J., BARBOZA, G., CAMPOS, L., OBANDO, J., AGUILAR, A. \& OBANDO, L., 1991: Cuencas sedimentarias de Costa Rica: Evolución geodinámica y potencial de hidrocarburos. - Rev. Geol. Amér. Central, 13: 25-59.

BARQUERO, R.MONTERO, W \& ROJAS, W., 1991: En: BARQUERO, R. \& BOSCHINI, I. (eds.) 1991: La crisis sísmica del Golfo de Nicoya y eventos sísmicos relacionados, Costa Rica 1990. - 135 págs. Inf. técnico de la Red Sismológica Nacional (R.S.N.).

BARQUERO, R. \& PERALDO, G., 1993: El temblor de Pejibaye de Turrialba del 10 de julio de 1993: aspectos sismológicos, neotectónicos y geotécnicos. - 32 págs., informe interno Instituto Costarricense de Electricidad, San José.

BARQUERO, R. \& ROJAS, W., 1994: Sismicidad inducida por el terremoto de Limón. Rev. Geol. América Central, vol. esp. Terremoto de Limón: 111-120.

BARQUERO, R., SOTO, G. \& LESSAGE, P. (eds.), 1992: Volcán Irazú. - 24 págs., inf. volcanológico período enero 1991 - mayo 1992, inf. interno ICE.
BORGIA, A., BURR, J., MONTERO, W., ALVARADO, G. \& MORALES, L.D., 1990: Fault propagation folds induced by gravitational failure and slumping of the Costa Rica Volcanic Range: Implications for large terrestrial and Martian edifices. - J. Geophy.Res., 95: 14357-14382.

BOSCHINI, I., ALVARADO, G. \& ROJAS, W., 1988: El terremoto de Buenavista de Pérez Zeledón (Julio 3, 1983): Evidencia de una fuente sismogénica intraplaca desconocida en Costa Rica. - Rev. Geol. Amér. Central, 8: 111-121.

DeMETS, C., GORDON, G, ARGUS, D. \& STEIN, S., 1990: Current Plate Motions. Geophys. J. Int. 101,2: 425-478.

DENYER, P. \& ARIAS, O., 1990a: Geología de la hoja Abra (mapa 1:50000) - Instituto Geográfico Nacional (IGN), San José, Costa Rica.

DENYER, P. \& ARIAS, O, 1990b: Geología de la hoja Candelaria (mapa 1:50000) - Instituto Geográfico Nacional (IGN), San José, Costa Rica.

DENYER, P. \& ARIAS, O., 1991: Estratigrafía de la región central de Costa Rica. - Rev. Geol. Amér. Central, 12: 1-59.

DENYER, P., ARIAS, O., SOTO, G. OBANDO, L \& SALAZAR, L., 1994: Mapa geológico Gran Area Metropolitana. - En: DENYER, P. \& KUSSMAUL, S. (eds): Atlas geológigo Gran Area Metropolitana. - 275 págs., Ed. Tecnológica de C.R., Cartago.

EBERHART-PHILLIPS, D., 1986: Three dimensional velocity structure in the northern California coast ranges from inversion of local earthquakes arrival times. - Bull. Seismol. Soc. Am., 76,3: 1025-1052. 
EBERHART-PHILLIPS, D., 1990: Three dimensional $\mathrm{P}$ and $\mathrm{S}$ velocity structure in the Coalinga region, California. - J. Geophys. Res. 95: 15343-15363.

FAN, G., BECK, S. \& WALLACE, T., 1991: The Seismic Source Parameters of the 1991 Costa Rica Aftershock Sequence: Evidence for a Transcurrent Plate Boundary. - J. Geoph Res. 98, B9: 15,759-15,778.

FISHER, D., GARDNER, T., MARSHALL, J. \& MONTERO, W., 1994: Kinematics associated with late Cenozoic deformation in central Costa Rica: Western boundary of the Panama microplate. - Geology, 22, 3: 263-266.

GOES, S., VELASCO, A., SCHWARTZ, S. \& LAY, T., 1993: The April 22, 1991, Valle de la Estrella, Costa Rica ( $\mathrm{Mw}=7.7)$ earthquake and its tectonics implications: a broadband seismic study. - J. Geophys. Res., 98, B5: 8127-8142.

GÜENDEL, F., 1985: Enjambres sísmicos en el volcán Irazú. Catálogo de temblores 1984. - Univ. Nacional Autónoma, Heredia, Costa Rica: 100-104.

GÜENDEL, F. \& PACHECO, J., 1992: The 1990-1991 seismic secuence across central Costa Rica: evidence for the existence of a micro-plate boundary connecting the Panama deformed belt and the Middle America Trench. - Eos Trans. Am. Geophys. Un. 73: 399.

HAVSKOV, J. \& LINDHOLM, C., 1992: The Seisan Earthquake Analysis Software. Ins. Solid Earth Physics, University of Bergen, Norway.

JACOB, K., PACHECO, J. \& SANTANA, G., 1991: Seismology and tectonics in Costa Rica, earthquake of April 22, 1991. - Reconnaissance Report, Earthquake Spectra, Supplement B, 7: 15-33.
LONSDALE, P. \& KLITGORD, K., 1978: Structure and tectonics of the eastern Panama Basin. - Geol. Soc. Amer. Bull, 89, 7: 981999

MATUMOTO, T., OTHAKE, M., LATHAM, G. \& UMAÑA, J., 1977: Crustal structure of the southern Central America. - Bull. Seismol. Soc. Am. 67,1: 121-134.

MINISTERIO DE INDUSTRIA, ENERGIA Y MINAS, DIRECCION DE GEOLOGIA, MINAS Y PETROLEO, 1982: Mapa geológico de Costa Rica. - Instituto Geográfico Nacional (IGN), San José, Costa Rica.

MINISTER, B. \& JORDAN, T., 1978: Presentday plate motions. - J. Geophys. Res. 83,A11: 5331-5354.

MONTERO, W., 1994: Sismicidad y Neotectónica, En: DENYER, P., KUSSMAUL, S. (eds): Atlas Geológico Gran Area Metropolitana: 147-160; Ed. Tecnológica de Costa Rica, Cartago.

MONTERO, W, 1994: Neotectonics and related stress distribution in a subduction-collisional zone: Costa Rica. - Profil, 7: 125-141.

MONTERO, W.\& ALVARADO, G., 1995: El terremoto de Patillos del 30 de diciembre de $1952(\mathrm{Ms}=5,9)$ y el contexto neotectónico de la región del volcán Irazú, Costa Rica. - Rev. Geol. Amér. Central, 18: 25-42.

MONTERO, W. \& DEWEY, J.W., 1982: Shallow-focus seismicity, composite focal mechanism, and tectonic of the Valle Central de Costa Rica. - Seis. Soc. Amer. Bull, 72: 1611-1626.

MONTERO, W., MADRIGAL, R., MORA, R., SEELEY, M., ALT, J. \& CLINE, M., 1991: Lineaments suggestive of recent fault activity. - Mapa no publicado, escala $1: 15000$. 
MONTERO, W. \& MORALES, L.D., 1984: Sismotectónica y niveles de actividad de microtemblores en el suroeste del Valle Central, Costa Rica. - Rev. Geof., Inst. Panam. Geogr. Hist., 21: 21-41.

MONTERO, W., PANIAGUA, S., KUSSMAUL, S. \& RIVIER, F., 1992: Geodinámica interna de Costa Rica. - Rev. geol. Amer. Central, 14: 1-12.

MONTERO, W., ROJAS, W., BOSCHINI, I., BARQUERO, R. \& FLORES, H., 1991: Neotectónica de la región de Puriscal. Origen de la sismicidad de mayo-diciembre de 1990. - Memoria del $5^{\circ}$ Seminario Nac. Geotécnia, San José , Costa Rica.

PANIAGUA, S., SALAZAR, L.G., KUSSMAUL, S., MONGE, A., BURGOS, A. \& FERNANDEZ, M., 1993: Amenaza y estimación económica básica de la vulnerabilidad material asociada al volcán Irazú Cordillera Central, Costa Rica. - 109 págs.; Inf. técn, Secc. Vulcanología, Escuela de Geología, Universidad de Costa Rica.

PLAFKER, G. \& WARD, S., 1992: Back Arc Thrust Faulting and Tectonic Uplift along the Caribbean Sea Coast During the April 22, 1991 Costa Rica Earthquake. - Tectonics, 11, 4: 709-718.

PROTTI, M., GUENDEL, F. \& McNALLY, K., 1994: The geometry of the Wadati-Bennioff zone under southern Central America and its tectonic significance: result from a high-resolution local seismographic network. - Phys. Earth Planet. Int., 84: 271-287.

PROTTI, M. \& SCHWARTZ, S., 1994: Mechanics of back arc deformation in Costa Rica: Evidence from an aftershock study of the April 22, 1991, Valle de la Estrella, Costa Rica, earthquake (Mw=7.7). - Tectonics, 13, 5: 1093-1107.

PROTTI, M., SCHWARTZ, S. \& ZANDT, G. (en prep.): Simultaneous inversion for earthquakes location and velocity sctructure beneath central Costa Rica.

SUAREZ, G., PARDO, M., DOMINGUEZ, J., PONCE, L., MONTERO, W., BOSCHINI, I. \& ROJAS, W., (1995): The Limón, Costa Rica Earthquake of April 22, 1991: Back arc thrusting and collisional tectonics in a subduction environment. - Tectonics, 14, 2: 518-530.

THURBER, C., 1983: Earthquake locations and three-dimensional crustal structure in the Coyote lake area, Central California. J.Geophys.Res., 88,B10: 8226-8236.

TRISTAN, F., BIOLLEY, P. COTS, C., 1912: The Sarchi earthquake, Costa Rica. - Bull. Seism. Soc. Am., 2: 201-210.

VIQUEZ, C., 1910: Temblores, terremotos, inundaciones y erupciones volcánicas en Costa Rica, 1608-1910. - 200 págs., Tipografía Avelino Alsina, San José. 